\title{
Pneumothorax caused by delayed tracheal rupture in a pediatric patient with acute respiratory distress syndrome
}

\author{
Minyoung Jung ${ }^{1,2}$, Jong $\mathrm{Ho} \mathrm{Cho}^{3}$, Ah Young $\mathrm{Choi}^{2}$, Minji Kim ${ }^{4}$ Joongbum $\mathrm{Cho}^{2}$ \\ Departments of ${ }^{1}$ Pediatrics, ${ }^{2}$ Critical Care Medicine, and ${ }^{3}$ Thoracic Surgery, Samsung Medical Center, Sungkyunkwan University School of Medicine, Seoul; \\ ${ }^{4}$ Department of Pediatrics, Hallym University Dongtan Sacred Heart Hospital, Hallym University College of Medicine, Hwaseong, Korea
}

Tracheal rupture is a potentially lethal complication of endotracheal intubation [1-3] and usually occurs shortly after intubation [4]. Such rupture presents as a linear tear and is caused by movement of an over-inflated cuff or stylet [5]. Herein, we describe a case of pneumothorax caused by tracheal rupture after 30 days of intubation. A previously healthy 8 -year-old boy was admitted to the pediatric intensive care unit for severe acute respiratory distress syndrome. The patient was treated with mechanical ventilation and extracorporeal membrane oxygenation. Cuff pressure was managed between 20 to $30 \mathrm{~cm} \mathrm{H}_{2} \mathrm{O}$, and the endotracheal tube was not changed before extubation. On hospital day 30, extubation was perfomred, and spontaneous breathing was noted. On the same day, massive pneumothorax was developed and was not controlled by chest tubes. Computed tomography showed a new lesion on the trachea (Figure 1), and bronchoscopy showed an oval ischemic lesion surrounded by a Cshaped tear (Figure 2). Since the position and size of the ischemic lesion were similar to those of the cuff, we suspected that prolonged cuff pressure created ischemia, and active breathing tore the weak margin. Managing cuff pressure in children requires high caution, and suspicion of tracheal rupture should be considered as a cause of pneumothorax.

\section{CONFLICT OF INTEREST}

No potential conflict of interest relevant to this article was reported.

\section{ORCID}

Minyoung Jung https://orcid.org/0000-0003-2851-9480

Jong Ho Cho https://orcid.org/0000-0003-3362-4621

Ah Young Choi https://orcid.org/0000-0002-9634-3950

Minji Kim https://orcid.org/0000-0001-5588-5414

Joongbum Cho

\section{AUTHOR CONTRIBUTIONS}

Conceptualization: MJ, JHC, AYC, MK, JC. Data curation: MJ, JHC. Writing - original draft: MJ, AYC. Writing - review \& editing: MK, JHC, JC.

Copyright (@) 2019 The Korean Society of Critical Care Medicine

This is an Open Access article distributed under the terms of Creative Attributions Non-Commercial License (http:// creativecommons.org/li-censes/by-nc/4.0/) which permits unrestricted noncommercial use, distribution, and reproduction in any medium, provided the original work is properly cited. 

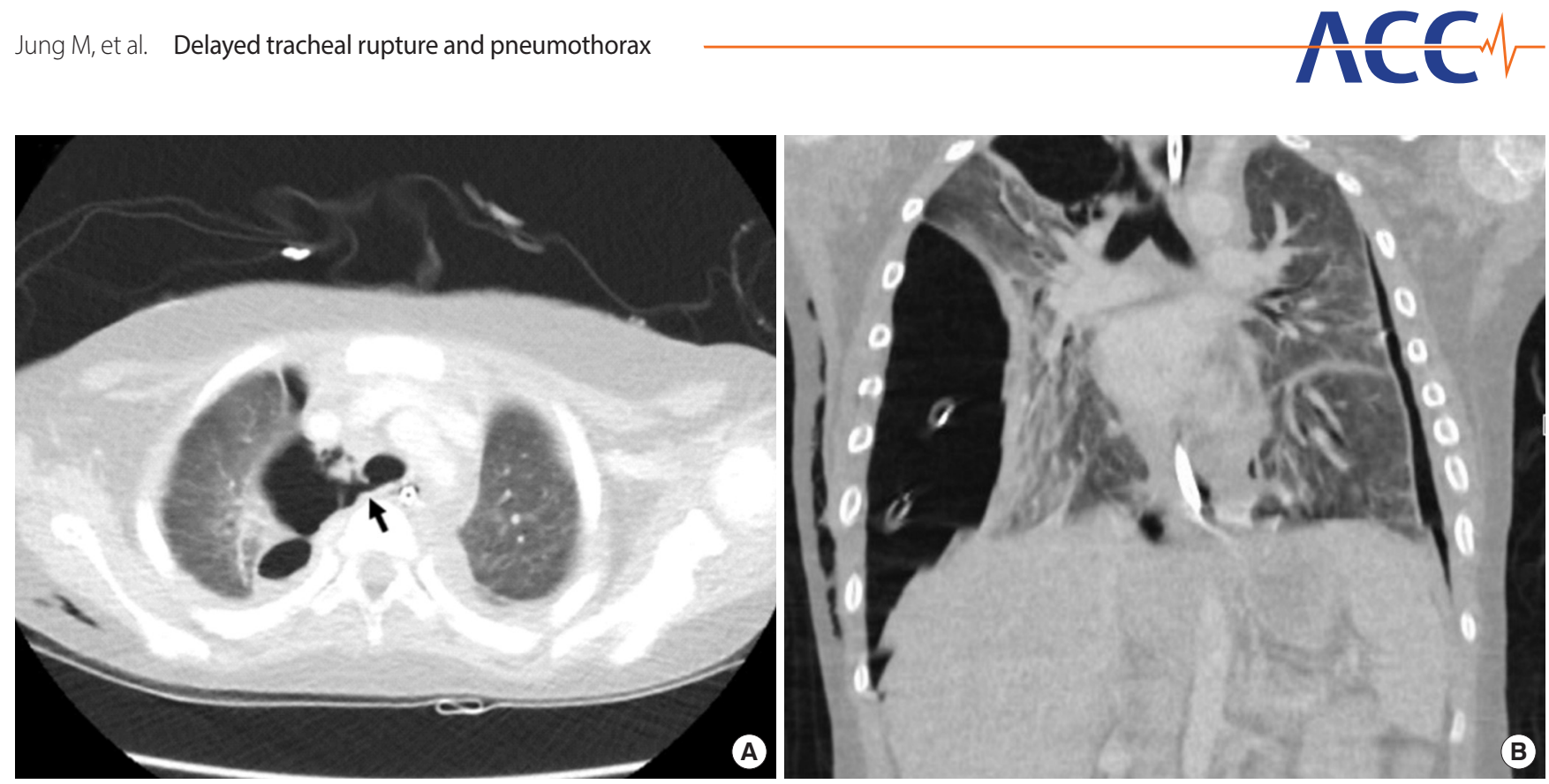

Figure 1. Chest computed tomography with post-contrast views. (A) A black arrow marks a 4-mm tracheal tear at the level of T3-4. Air collection is also presented on sagittal view. (B) Tracheal rupture appears above the carina on the right side.

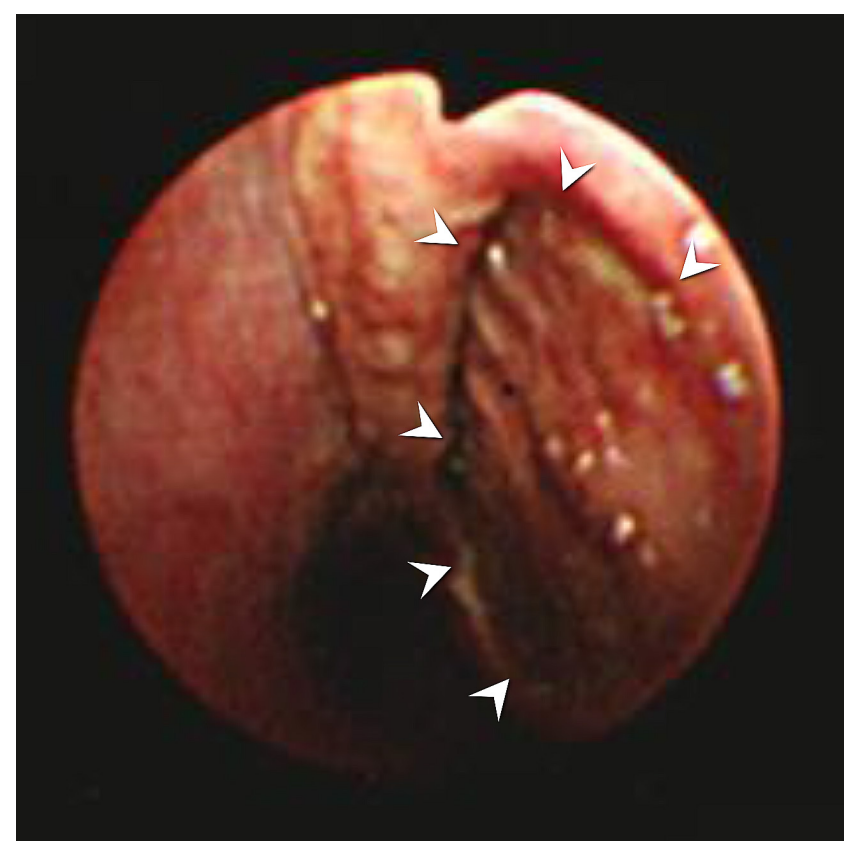

Figure 2. Bronchoscopic findings. A C-shaped tracheal rupture (white arrowheads) around the oval ischemic lesion at the posterior membrane of the lower third of the trachea.

\section{REFERENCES}

1. Hofmann HS, Rettig G, Radke J, Neef H, Silber RE. Iatrogenic ruptures of the tracheobronchial tree. Eur J Cardiothorac Surg 2002;21:649-52.

2. Schneider T, Storz K, Dienemann H, Hoffmann H. Management of iatrogenic tracheobronchial injuries: a retrospective analysis of 29 cases. Ann Thorac Surg 2007;83:1960-4.

3. Minambres E, Buron J, Ballesteros MA, Llorca J, Munoz P, Gonzalez-Castro A. Tracheal rupture after endotracheal intubation: a literature systematic review. Eur J Cardiothorac Surg 2009;35: 1056-62.

4. Jabre P, Avenel A, Combes X, Kulstad E, Mazariegos I, Bertrand L, et al. Morbidity related to emergency endotracheal intubation: a substudy of the KETAmine SEDation trial. Resuscitation 2011;82:517-22.

5. Lim H, Kim JH, Kim D, Lee J, Son JS, Kim DC, et al. Tracheal rupture after endotracheal intubation: a report of three cases. Korean J Anesthesiol 2012;62:277-80. 